\title{
Forclusão do feminino na organização do trabalho: um assédio de gênero
}

\author{
Marie-Grenier Pezé, dra. \\ Hôpital Max Forestier \\ 303, Av. De la République \\ 92200 Nanterre França \\ E-mail:mariepeze@free.fr
}

\begin{abstract}
Resumo
Neste artigo é proposta uma discussão para ajudar a compreender a temível eficácia do assédio moral no trabalho. Para tanto é discutida a questão da construção "identitária", que depende do reconhecimento que se dirige sobre o fazer, a identidade é inseparável dos gestos técnicos efetuados pelo sujeito. Esta também é uma questão de gênero de pertencimento a um sexo. Em psicodinâmica do trabalho, uma atenção particular é dada à construção dos coletivos de trabalho que soldam um grupo em torno de regras da profissão. A cooperação necessita um ajustamento dos procedimentos singulares de execução da tarefa, mas também uma confrontação de posições éticas de cada um, sobre a base de uma confiança partilhada e, portanto, de uma cooperação possível. Entretanto o assédio moral se tornou uma verdadeira estratégia de gerenciamento, baseada na radicalização das novas formas de organização do trabalho que favorecem a virilidade defensiva, que parecem ter transformado profundamente as relações nos grupos de trabalho e radicalizado os sistemas de defesa construídos para resistir.
\end{abstract}

\section{Palavras-chave}

Psicodinâmica do trabalho, organização do trabalho, assédio moral, gênero, construção "identitária"

\section{Female foreclusion in work organization: gender harassment}

\begin{abstract}
This paper proposes a discussion to help understand the fierce efficacy of moral harassment in the workplace. For this, the issue discussed is that of identitary construction, which depends on the acknowledgement directed on doing, since identity is inseparable of the technical gestures conducted by the subject. This is also a gender issue, of belonging to a sex. In work psychodynamics, a special attention is given to the construction of work collectives which weld a team to professional rules. Cooperation needs an adjustment of particular procedures for carrying out a task, but it is also a confrontation of each individual's ethical positions, based on shared trust and, therefore, of possible cooperation. Nevertheless, moral harassment became a real management strategy, based on the radicalization of the new forms of work organization which favor defensive virility, which seem to have deeply transformed the relationships within the work teams and radicalized the defense systems built to resist it.
\end{abstract}

Key words

Workplace psychodynamics, work organization, moral harassment, gender, identitary construction. 
É habitualmente a construção de um corpo erótico no entrelaçado das identificações que apaixona o psicanalista. Mas limitar seu olhar terapêutico à construção do corpo erótico através dos acasos da história infantil enquanto que o trabalho (sua regulamentação, seu custo, seus efeitos psíquicos e orgânicos) penetra fortemente o material clínico é manter uma postura ilusória.

Uma psicanalista durante uma consulta «Sofrimento e trabalho» pode esperar ver o assédio moral evocado na prática clínica. A presença na mídia desta nova denominação deu uma forte força às queixas das vítimas, a criação de uma rede especializada de escuta e de cuidados, lhes deu doravante uma legitimidade social. Do que se trata essa legitimidade psicopatológica? É necessário lembrar-se que o assédio moral (HIRIGOYEN, 1998) é um procedimento técnico de destruição e não uma síndrome clínica.

Nós privilegiaremos aqui a definição de Michèle Drida : "O assédio é um sofrimento infligido no local de trabalho de maneira durável, repetitiva e/ou sistemática por uma ou várias pessoas a uma outra pessoa, por todos os meios relativos às relações, à organização, aos conteúdos ou às condições de trabalho, mudando a sua finalidade, manifestando assim uma intenção de prejudicar ou mesmo de destruir." (DRIDA, et al. 1999).

Como compreender a temível eficácia do assédio moral sem compreender o jogo identitário ligado à situação de trabalho? O que confere ao trabalho sua dimensão propriamente dramática é sua ligação com a construção "identitária". Quando a escolha da profissão está de acordo às necessidades psicossomáticas de um sujeito, quando as modalidades do seu exercício permitem o livre jogo de funcionamento mental e da construção pulsional individual, o trabalho ocupa um lugar central na manutenção de uma economia psicossomática durável (DAVEZIES 1993). Porque o reconhecimento do trabalho se dirige sobre o fazer, a identidade é inseparável dos gestos técnicos efetuados pelo sujeito. Atos de expressão da postura psíquica e social do sujeito dirigido ao próximo (DEJOURS, DESSORS, MOLINIER, 1994), eles se ancoram na nossa infância pela cópia, pois a identificação aos modelos amados e admirados, na tradição das profissões transmitidas pelo aprendizado, entrelaçando as ligações estreitas entre atividade do corpo e o pertencimento a um coletivo de trabalho. Enfim, eles traduzem nossa identidade de gênero, nosso pertencimento a um sexo.

\section{O ASSÉDIO MORAL, UMA ESTRATÉGIA DE GERENCIAMENTO SEXUADO}

"Enquanto você não parar de escalar, os degraus não cessarão de subir ao mesmo tempo que seus passos avançam" Kafka, O processo

Os gestos de uma profissão são a fonte fundamental de estabilização da economia psicossomática, oferecendo à excitação pulsional uma saída socialmente positiva ao valor da sublimação. Tornar sua execução aleatória, paradoxal, humilhante, dia após dia, tem efeitos traumáticos sobre a psique. A subordinação própria à definição jurídica de contrato de trabalho prende o assalariado numa toxicidade contextual experimental. Com efeito, o aparelho psíquico só pode se afrontar a uma situação excessiva fonte de excitação graças a duas grandes vias de expressão: o pensamento, que permite trabalhar o "excesso" intrapsíquico, o movimento, que descarrega o corpo do excesso de tensão. Numa situação de assédio, a repetição das humilhações aos novatos, os vexames e as injunções paradoxais têm valor de destruição psíquica e suspendem todo trabalho do pensamento. A impossibilidade de demitir-se sob pena de perder seus direitos sociais barra a descarga sensório-motora. O impasse criado nestas duas grandes vias de escoamento das excitações traumáticas convoca fatalmente a ruína depressiva e a via somática mais ou menos a longo termo. Nós veremos mais adiante como, tocando os gestos da profissão, nós ferimos fatalmente as pessoas na sua identidade.

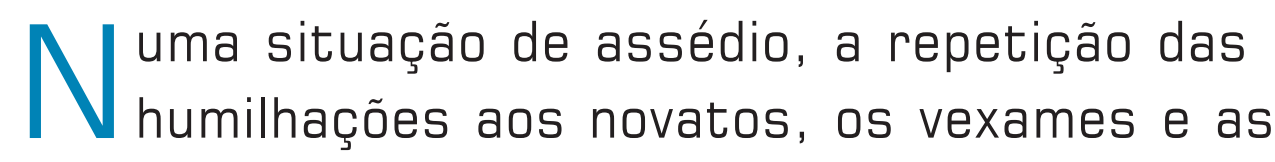
injunções paradoxais têm valor de destruição psíquica e suspendem todo trabalho do pensamento.

A situação do assédio, quando interrompida a tempo, pode manter um parêntese obscuro na vida do sujeito. Quando ocorre por um tempo excessivo, as seqüelas psíquicas (neurose traumática, ruína ansio-depressiva, acessos delirantes), acometimentos orgânicos (amenorréias, câncer de seio, de ovário entre as mulheres) podem ser definitivos e constituem um problema de sobrevivência individual e de saúde pública maior.

Em psicodinâmica do trabalho, uma atenção particular é dada à construção dos coletivos de trabalho que soldam um grupo em torno de regras da profissão. A cooperação necessita um ajustamento dos procedimentos singulares 
de execução da tarefa, mas também uma confrontação de posições éticas de cada um, sobre a base de uma confiança partilhada e, portanto, de uma cooperação possível. Uma análise aprofundada da situação de impasse descrita pelos pacientes assediados coloca em evidência o isolamento do sujeito. Isolamento de fato num posto sem equipe, isolamento subjetivo num posto onde o coletivo de trabalho não existe verdadeiramente, onde falta cooperação, e mais ainda a solidariedade. Suportar o trabalho deixa o sujeito sozinho com seus mecanismos de defesa individuais, privando-o do recurso das estratégias coletivas de defesa. Estas últimas, destinadas a fazer frente ao sofrimento no trabalho, são específicas a cada local profissional, produzidas, estabilizadas e construídas coletivamente. Se o sujeito isolado não pode beneficiar-se delas, ele pode ser atingido, ou servir, pelo seu estado, de bode expiatório dos outros.

A precariedade tende a neutralizar a mobilização coletiva, a produzir o silêncio e o "cada um por si". O medo de perder seu emprego induz as condutas de dominação e de submissão. É necessário constatar que a manipulação deliberada da ameaça, da chantagem, do assédio tem sido utilizada como um método de gerenciamento para desestabilizar, incitar o erro e permitir o afastamento por uma falta ou incitar a demissão. Alguns se queixam do assédio que alguns meses antes eles viram ser exercido sobre outro sem intervir ou, muito pior, para guardar seu lugar e contribuindo para que isso acontecesse.

Nestas situações, o sofrimento ético resulta, de um lado, da pulverização da auto-estima, e ainda da culpabilização às avessas do outro sem que ele tenha sido defendido.

ologias defensivas da profissão. Um homem, um verdadeiro homem, deve para ter sucesso chegar a ignorar o medo e o sofrimento, o seu e o do outro. A virilidade social se mede pela capacidade de exercer sobre os outros violências anunciadas como necessárias, num sistema de construção social do masculino que desperta o medo de ser castrado, submetido, passivo, afastado, privado de seus atributos. Quanto mais as condições de trabalho se endurecem, mais as defesas se enrijecem, chegando a haver uma exacerbação das atitudes viris.

O machismo induzido pela organização do trabalho não fica no vestiário quando se deixa o local de trabalho. Para mantê-lo a postos é necessário, por vezes, colocar um impasse sobre sua vida afetiva. A organização do trabalho, quando ela exige defesas adaptativas, pode afetar a organização mental do sujeito até mesmo na sua construção erótica, nas suas relações afetivas. A falta de reciprocidade nas relações intersubjetivas entre os homens e as mulheres no trabalho é levada para a vida no lar. O "fora do trabalho" traz também marcas de deformações de comportamentos sexuais no trabalho. “(...) pelas suas observações, suas condutas, as mulheres fragilizam a negação do medo colocando em perigo sua base principal :o prestígio viril" (MOLINIER, 1997).

\section{DELPHES OU « A CONFUSÃO ORGANIZADA » :}

O primeiro encontro com o sujeito assediado é carregado de olhares múltiplos: encontro com o sujeito, sua estrutura psíquica, sua organização do trabalho, sua forma de descompensação. Estes níveis de escuta intrincados exigem concentração, formação especifica sobre a organização psíquica individual e a organização do trabalho. Esta investigação psicodinâmica é um momento privilegiado, podendo conduzir o sujeito à compreensão dos mecanismos específicos utilizados contra ele, ao descolamento da história do trabalho e da his-

Para conjurar o risco de descompensação psíquica, a maior parte dos sujeitos constrói defesas específicas. A vergonha é superada pela interiorização dos valores propostos, pela banalização do mal no seu exercício dos atos civis comuns (DEJOURS 1999). O cinismo no mundo do trabalho é então considerado equivalente à coragem, à força de caráter. A tolerância à injustiça e ao sofrimento infligido ao outro é construída em valores viris, em ide- tória singular, à verbalização e à perlaboração dos afetos reprimidos. $\mathrm{O}$ paciente passa por uma provação porque a entrevista é longa, o retorno a uma cronologia de acontecimentos laborais, a catarses dolorosas.

Delphes cai sobre ela mesma, hesitante, conta sua historia sem cronologia, sem lógica ao ponto que eu mesma me perco pouco a pouco. Um grande sofrimento surdo do corpo e a palavra aleatória desta mulher, mas eu 
não chego a nada com o material que ela traz. Eu tento algumas questões para inserir alguns pontos de sinalização precisos sobre este itinerário profissional. Eu custo a acreditar que o funcionamento intelectual e imaginário desta jovem mulher engenheira poderia estar tão alterado. A descompensação ansioso-depressiva é grave. Há alguma coisa a mais, da ordem do verdadeiro e do falso, do real e do irreal, do justo e do injusto que ela não sabe mais situar. Ela está no limite da perda da realidade, desorganizada psiquicamente. O tempo passa e o sentimento de visco psíquico persiste ao ponto que eu decido terminar a entrevista que durou duas horas. Duas horas!

Nos dias que se seguem, chega uma primeira carta, depois outras. Começa então uma correspondência unilateral, uma vez que eu não respondo. Eu recebo páginas numeradas que se acumulam. Eu me torno a depositária de um espaço psíquico onde se anuncia uma reconstrução identitária. Da massa disforme inicial emergem pouco a pouco os contornos de uma vida de mulher. Delphes se extrai, diz ela, da "confusão organizada" onde ela estava perdida. Observando o fio condutor das cartas desde o início, o desaparecimento das faltas de acordo, de gênero, a aparição de espaço entre palavras onde elas estavam coladas, o retorno de uma cronologia dos acontecimentos. No fundo, Delphes descreve o trabalho com a minúcia de uma verdadeira profissional e a impecável representação de mulher que lhe é imposta. Esta correspondência de vários meses permitirá a elaboração multidisciplinar ${ }^{2}$ de um atestado argumentando o assédio de gênero e suas consequiências psicopatológicas, apoiando o médico do trabalho na sua diligência de colocar restrições à paciente "todas as tarefas na empresa que podem trazer perigo imediato" (artigo R 241-51-1 do código do trabalho francês).

Contratada numa grande empresa com um diploma universitário técnico em engenharia elétrica e informática, a paciente descreve um percurso profissional satisfatório no seio da empresa antes de 1990. Ela é autônoma na gestão da sua tarefa, sua hierarquia direta confia nela. Ela gosta muito de aprender. No contrato, seu chefe de serviço the precisou, entretanto, que como era uma mulher, e portanto uma mãe em potencial, ela não teria o mesmo salário que os homens.

Desde 1990, as ameaças de afastamento foram freqüentes. A organização do trabalho se radicaliza. De "nós trabalhamos para a pátria-mãe" passaram a "nos iremos trabalhar como os japoneses". O ambiente de trabalho foi ficando mais duro. As horas de trabalho aumentaram, ela precisava freqüentemente se mudar. Ela era, entretanto, a única que possuía um antigo contrato tratado diretamente. Cedo ela deve gerir dois tipos de contrato de trabalho ao mesmo tempo. A necessidade de adaptação ao trabalho é constante. Em 1983, ela trabalha à mão, sobre papel vegetal, com lápis HB, caneta Rotring ${ }^{\circledR}$; em 1999, ela trabalha diretamente com o computador, olhar sobre a tela, com o mouse. Cada contrato demanda uma reflexão, sobre evolução, a utilização e a proteção do material vendido. Os tempos de realização só diminuem. Trabalhar rápido com as pessoas que nem sempre tem a competência necessária se torna uma ilusão.

Ela nunca teve a escolha da tarefa que deveria realizar. O trabalho era aquele que os homens não haviam escolhido. Delphes deve conceber um sistema automático em seis meses. O sistema a ser realizado é aquele que ninguém quis fazer, previam, conforme lhe disseram, que seriam necessárias no máximo, 600 linhas de cálculo. Ela fez uma avaliação e totalizou de fato 1.400 linhas de cálculo. Isto significa encomendar o material para dois sistemas e não para um só, 12 meses de trabalho. Ela coloca em questão a prescrição da hierarquia, sua tarefa de trabalho parece sempre mais importante que a dos homens porque ela não esconde as dificuldades reais. Ela tem que se virar.

\section{RADICALIZAC̣ÃO DA ORGANIZAC̣̃̃O DO TRABALHO E A VIRILIDADE DEFENSIVA}

Delphes assume há muito tempo as funções de um cargo superior, mas com um salário inferior, ela precisou esperar cerca de seis anos para receber a promoção. Ela não tem o diploma universitário de engenheira plena e enquanto mulher não tinha apoio da hierarquia. Os outros que não tem o mesmo cargo à sua volta lhe dizem "é porque você dorme com o chefe que você passou para este cargo!".

A partir da promoção, ela precisa se afirmar, ter um perfil de autoridade. "Na empresa, eles consideram o estresse como um estimulante. O estresse é então vivamente estimulado para que cada executivo o provoque afim de obter melhores resultados." Os executivos masculinos the transmitem esta filosofia que ela deve doravante aplicar: "Você está lá para incitá-lo. Quando nós estamos na casta superior, é para obedecer". Seu chefe direto a incita a práticas gerenciais: "Nós iremos dar alguém para você treinar diretamente. Você tem a proteção da hierarquia". Se afirmar em cima de qualquer um consiste em "fazer pressão" sobre alguém que ocupa um nível hierárquico inferior, lhe dar metas irrealizáveis, sem meios e com pouco tempo para realizálas e lhe dizer que é uma competição. Fazer também a pressão quando as pessoas entram em férias. Afirmar sua autoridade sobre os outros passa por este tipo de relações "viris" enquanto que "meu conceito de autoridade enquanto mulher passa pela relação", afirma a paciente, "pela cooperação, por considerar o outro e suas competências profissionais". 
A nova organização do trabalho parece ter transformado profundamente as relações nos grupos de trabalho e radicalizado os sistemas de defesa construídos para resistir. Os homens encontram certamente as mesmas dificuldades que Delphes em termos de constrangimento de tempo, de trabalho feito sem os meios adequados. No entanto, eles parecem suportar "esta confusão organizada" pela interiorização massiva dos novos valores da empresa e a adesão a uma ideologia defensiva da profissão baseada sobre o cinismo. Sabemos que "são as ideologias defensivas da profissão que produzem a expressão especifica da virilidade no trabalho, no inicio essencialmente voltadas à defesa contra o sofrimento, se mostraram num segundo tempo utilizáveis para aumentar a produtividade." (DEJOURS 1988). Podemos então fazer a hipótese que a oscilação da estratégia defensiva em ideologia, passe por um programa de ação coletiva específica. Além disso, uma técnica de interrogatório pesado sobre o assalariado é introduzida como método específico de gerenciamento. Praticada a dois, ela responde aos métodos de desestabilização do interrogatório policial: nível verbal elevado e ameaças, chuva de questões sem possibilidade de serem respondidas, clima de acusação sistemática, falsas saídas, duração prolongada da entrevista, porta deixada aberta para todos ouvirem. Isso é feito para se obter o rebaixamento emocional do assalariado e de todos aqueles que escutaram.

1997). O perigo é projetado fora do grupo sobre um bode expiatório, no ataque exterior da diferença: "o deficiente", "o negro", "a mulher". Sendo a única mulher na equipe, o assédio de Delphes se torna inexoravelmente sexista.

\section{A REPRESÃO DE SI}

Pede-se a Delphes que se ocupe dos clientes estrangeiros que têm reconhecidamente posições machistas diante das mulheres. Sua percepção do trabalho é fina : "Tratase de contratos feitos pelo pessoal de venda, é traduzi-los em trabalho real, para os técnicos onde a técnica evolui sem parar, para satisfazer os clientes de raízes e de expressões socioculturais diferentes". É então a ela que são confiadas as mediações difíceis porque ela se desdobra nas suas qualidades relacionais de antecipação, de mediação, de empatia. Em resumo, suas qualidades "femininas" inerentes à condição de mulher. Um dos chefes lhe afirma sarcasticamente que ela foi escolhida para colocá-la em situações delicadas com os homens que vêm de países onde as mulheres são maltratadas. De fato, os clientes indianos, paquistaneses, indonésios, egípcios, chineses se dizem todos honrados de trabalhar com uma mulher ocidental. Os homens estrangeiros em situação de aprendizado se preocupam, sobretudo em não decepcioná-la. Desde o início, as competências de formadora que ela utiliza são invisíveis porque são ligadas à "natureza feminina" e não originadas de seu trabalho e de suas competências pessoais.

A ideologia defensiva da profissão enaltece diante das mulheres uma posição de poder e de conhecimento. “(...) o desprezo das mulheres, o machismo, encontram assim uma potente alavanca na contribuição que traz à negação da vulnerabilidade dos homens" (MOLINIER 1997). A mulher é por natureza inferior,

Estas técnicas pesadas são valorizadas pelos homens. O exercício autorizado da agressividade é um sistema de governo dos homens que solda o coletivo de trabalho em torno de uma radicalização defensiva. "A defesa transformada em um fim em si, a luta contra o sofrimento se transforma em alienação, impedindo todas as possibilidades de expressão individual, em proveito de uma indiferenciação dos membros do coletivo" (MOLINIER psicologicamente e intelectualmente. Esta afirmação é confirmada por afirmações picantes, que Delphes escuta dia após dia: "Somente uma mulher perguntaria estas coisas!", "Se isso acontece, é por culpa da mulher", "para uma mulher você é muito bem paga!", "Corte seus cabelos, é como se fazia com as há sistematicamente problemas...", "De todas as maneiras, não é necessário procurar, tem somente uma mulher na parada...". Ela 
está esgotada, não pesa mais do que $45 \mathrm{~kg}$. Uma tecnóloga em plena atividade, a menos adaptada, uma demanda incessante para assumir horas extras são ainda fatores agravantes do seu esgotamento. Não é mais informada das reuniões: reunião de lançamento, reunião sobre o desenvolvimento dos negócios, reunião com os mecânicos. Contrariamente aos outros chefes, ela não tem um computador exclusivo, ela trabalha no de qualquer outro colega. Ela é colocada como invisível, excluída pelo boicote subterrâneo presente.

A solidão fica maior sobre os planos intelectual e intersubjetivo. O mecanismo de defesa que ela desenvolve para resistir é a repressão. Ao contrário do recalque que permite, num processo inconsciente, não considerar nossos desejos e os conflitos que eles suscitam em nós, a repressão é um trabalho consciente e constante do ego, um esforço voluntário e deliberado para deixar de lado as representações conflituosas e os afetos correspondentes. A repressão educativa é um exemplo perfeito: pelo gesto, palavra, olhar, trata-se de pesar sobre as expressões motoras e verbais de uma criança, de indagar sua espontaneidade e seus ímpetos pulsionais. Ainda mais longe, de pesar sobre o pensamento e as fantasias desenvolvendo então as limitações funcionais do ego (PARAT, 1991). Delphes tenta se fazer pequenina, se apagar. A única mulher num coletivo de homens, ela não pode partilhar sua feminilidade. Ela só usa calças, ela suprime as bijuterias, seu cabelo é neutro. Os bloqueios à formação, a falta de estabilidade dos cargos propostos, a desqualificação constante de seu trabalho a impedem de encontrar uma saída que valorize seu funcionamento pessoal.

Em paralelo, as regras da empresa estipulam que não se pratique nenhuma discriminação em relação aos empregados em razão da sua raça, sua religião, suas opiniões políticas ou de seu sexo, que todos se engajem e tratem os outros com dignidade, respeitando plenamente a vida privada dos colegas.

Pela falta de referencias para pensar o que vem do exterior, do campo social, Delphes acredita que a causa de seu sofrimento seja intrapsíquica e se responsabiliza, portanto. Ela começa uma psicoterapia e encontra um espaço para pensar suas dificuldades. Passado um certo tempo, ela encontra um esquema explicativo. Eles, os homens, têm uma lógica que ela não compreende. Ela fica então enfraquecida, não confiável, insuficiente, impotente. Por esta posição feminina defeituosa, confrontando a hipótese de um masoquismo inconsciente, ela se convence da legitimidade do poder dos homens. Esta aceitação da interiorização de uma posição enfraquecida tem efeitos positivos em termos de benefícios secundários pois ela autoriza um "deixa disso". Ela decide pedir tempo parcial porque a sobrecarga crônica de trabalho deixou marcas na sua vida privada. Seus dois filhos têm dificuldades. Ela faz também um pedido de utilização de bônus, previsto no contrato. Ela é convocada pelo seu diretor de recursos humanos que lhe assinala que ela é a primeira a reclamar seus bônus, mesmo que isto esteja previsto no contrato, que isto não deveria ser sabido, que ele "não tem que gerenciar ainda mais os dias para recuperação dos bônus destas damas". A não convergência na prática social dos homens e das mulheres sobre o tempo fora do trabalho fica caricatural diante do pedido de tempo parcial e de utilização dos bônus. O pedido é incompreensível para seu chefe, que lhe faz doravante críticas cotidianas.

A partir desta data, seu trabalho é desqualificado. Ela faz os trabalhos que ninguém quer fazer. A descompensação está presente sob a forma do esgotamento profissional, mas combatida sem trégua para manter o trabalho e não desabar. O estado geral se agrava. Os sintomas físicos começam sempre pelas vertigens: "Tudo gira em torno de mim, eu me torno transparente, eu não escuto mais nada de fora, eu não sinto mais minhas pernas e a vontade de chorar está lá. Eu vejo grandes buracos negros diante de mim. Eu tenho a forte sensação de estar em perigo, eu não tenho mais forças, mais vontade de comer e às vezes tenho idéias suicidas".

Quando voltou de férias, em setembro, ela tinha seu novo contrato, mas ela não aparecia mais no organograma. O chefe não era um executivo e lhe exprime além disso seu incômodo diante dela. Os membros da equipe se dirigem, no entanto, a ela quando surge alguma dificuldade. O mau funcionamento do coletivo de homens deve ser suportado pelas mulheres. "30 homens diante de uma mulher deve ser uma situação muito tranqüilizadora para escapar do conflito" diz Delphes, que deve gerir psiquicamente esta contradição: suportar as imagens de vaginas de mulheres peladas em destaque na tela de descanso dos computadores de seus colegas e permanecer como mediadora compreensiva.

Ela é sem trégua o centro das atenções diante da equipe. $\mathrm{O}$ chefe vem the falar se encostando nela e lhe dizendo a $25 \mathrm{~cm}$ de sua boca. "Este homem que se encosta quando fala, é o horror tanto que cheira mal. Isto ocorre diversas vezes, quanto mais eu me afasto mais ele se aproxima de novo. Ele cheira mal, ele é grosseiro, ele não escuta. Eu lhe digo que não sou surda, que desejo mais distância entre nós." Seu chefe de serviço, a quem ela se queixa das telas pornográficas e do gestual fora de lugar do chefe direto, lhe responde: "Isto é sempre assim e eu não posso mudar nada".

Ela se concentra sobre a tarefa que lhe é prescrita. Ela começa a avaliar o volume de trabalho, o cronograma de 
tarefas, o programa de computador necessário, os colegas que podem ajudá-la. O colega ocupado de estudos se recusa a lhe comunicar as informações. A ela é imposto um novo prazo muito curto. O planejamento e a gestão deveriam ser assumidos pelo chefe direto. Nada foi feito. Uma vez mais, lhe é confiada uma tarefa que ela não pode executar, lhe é fixado um objetivo impossível de atingir. $\mathrm{O}$ assédio é manifesto: desqualificação do cargo, sobrecarga de trabalho, injunções paradoxais, fracassos pelos objetivos irrealizáveis. As conseqüências da alteração de sua relação com o real do trabalho são maiores sobre seu equilíbrio psicossomático. No dia seguinte, as dificuldades graves fazem seu médico decidir afastá-la por tempo prolongado.

\section{FORCLUSÃO DO FEMININO E ORGANIZAC̣ÃO DO TRABALHO:}

Vários meses se passaram. Novamente ela vem me ver porque eu devo lhe dar um certificado de apoio à ação do médico do trabalho atestando sua incapacidade devido ao perigo imediato. Ela diz que se sente melhor desde que está em licença médica, que seus transtornos desapareceram, que seu corpo se recuperou: "até minha menstruação voltou!". Eu lhe pergunto: "Você não tinha mais menstruação?".- Sim. "Desde quando?". Ela fica perturbada, precisa refletir longamente para lembrar o começo da amenorréia, suas interrogações para sua ginecologista que lhe repetia "isto pode voltar" . Ela encontra a data no seu prontuário médico: 1989. Nós nos remetemos ao período da radicalização na organização do trabalho, a acentuação das ideologias defensivas viris tinham começado com a designação de um bode expiatório, sobre o ataque sistemático ao feminino.

Para ter uma chance de encontrar as condições propicias ao reconhecimento de suas qualidades profissionais e à realização de si no trabalho, Delphes deveria compor com a economia erótica de seus colegas homens. Muitas mulheres fracassam nesta luta que as dilacera interiormente entre sua identidade de mulher e sua identidade no campo social. O problema é quando isto faz perder sua feminilidade. A descompensação depressiva e somática de Delphes resulta deste conflito. Ela recusou endossar o arsenal machista, não demonstrou sua capacidade de trazer uma contribuição entusiasta ao funcionamento da estratégia viril e se viu excluída. O desaparecimento da sua menstruação assinala o assédio de gênero ao nível somático, pontuando a função erótica reprimida. À virilidade anexada pelo vocabulário agressivo e sumoso, o gestual invasivo, os comportamentos agressivos, as telas pornô que solicitam a economia erótica masculina nas suas pulsões parciais, Delphes parece responder pela neutralização de sua identidade sexuada até no nível somático.

$\mathrm{Na}$ perspectiva psicossomática, a descompensação testemunha geralmente a fragilidades das possibilidades de representação, do transbordamento das capacidades de ligação da psique, de uma situação de impasse para o sujeito. "A somatização é um processo pelo qual o conflito que não pode encontrar saída mental vai desencadear no corpo desordens endócrino-metabólicas, ponto de partida de uma doença orgânica" (DEJOURS 1993).

Sabemos que as relações das crianças com seus pais vão, numa interação incessante, ao coração dos gozos e das mágoas, inscrever a trama da nossa historia emocional sobre o corpo biológico, edificar assim nosso segundo corpo, o corpo erótico. Certas zonas e/ou funções corporais podem no entanto permanecer sobre o primado do psicológico fruto de terem sido subvertidos em proveito da economia do desejo. A "forclusão"3 (DEJOURS 1995) destas zonas ou funções fora da edificação do corpo erótico assinalam o fracasso da subversão libidinal de uma função biológica. Estas zonas brancas são os lugares de eleição de uma desorganização psicossomática, desde que na relação com o outro, na esfera privada, como no trabalho, elas sejam solicitadas. A "escolha do órgão ou da função", traz então a marca do impasse do trabalho psíquico, estrutural ou conjuntural. Entre numerosas mulheres em situação de assédio, a anamnese permite reencontrar problemas na esfera ginecológica: amenorréia, metrorragias, ou ainda mais graves, como câncer do colo, do ovário e do útero. Para Delphes, ao tornar invisível sua identidade feminina, o ataque cotidiano a suas características psíquicas, psicológicas, a suas competências profissionais, acarretou uma lenta e inexorável desconstrução da complexidade pulsional. O processo de construção da identidade sexual parte do corpo, se apaga.

Quais espaços as exigências de identidade social no trabalho deixam para a construção do masculino e do feminino? O mundo do trabalho é atravessado pelas relações sociais de sexo, definindo as condutas e as representações de mundo que não são sexuais no sentido psicanalítico do termo; o sistema consciente que se constrói lá, se edifica em detrimento do sistema pré-consciente como alças restritas de determinismos, deixando geralmente pouco lugar aos rearranjos psíquicos individuais. $\mathrm{O}$ encontro entre a organização psíquica individual e a organização do trabalho não é uma imagem. As relações de trabalho têm uma lógica, modos de funcionamento precisos, uma duração que exige um engajamento total, implicando na renúncia de todo o resto. Este resto poderia ser a finalização da construção do corpo eróti- 
co. O trabalho de bissexualização psíquica, o encontro com o outro podem ser colocados num impasse em proveito de uma identidade sexual de superfície, socialmente construída, jamais definitivamente adquirida, visto que imposta do exterior no lugar de identificações internas (PEZÉ, 1998). No entanto, a construção identitária social não tem a mesma equivalência para os homens e para as mulheres.

Em período de "guerra econômica", quanto mais as condições de trabalho se endurecem, mais as defesas se enrijecem empurrando as atitudes viris à caricatura, contaminando as relações com as mulheres com estereótipos que servem a se manter no trabalho. A exacerbação do sentimento de força e de poder exercidos entre os homens, se exerce então contra as mulheres. "A luta contra o medo e o sofrimento encontra, para os homens, sua eficácia simbólica no sistema de representações que estrutura um imaginário social associando a supremacia dos homens ao domínio infalível do real. Em permitindo a integração no coletivo do trabalho, a virilidade social se capitaliza no registro da identidade sexual e confere segurança, prestígio, esperança de sucesso com as mulheres àquele que é reconhecido pelos outros homens como um deles" (MOLINIER, 1997)

Pelo simples fato da sua presença, as mulheres podem constituir um perigo maior visto que a virilidade se edifica por contraste sobre a inferioridade da mulher. A única mulher no coletivo de homens, Delphes, pelo fato de não ser um chefe como deveria, de não poder se tornar a mãe ou a mascote, vertentes femininas aceitáveis, se tornou assexuada. A transparência de Delphes não foi um máscara, mas uma figura do vazio.

\title{
Tradução: Selma Lancman
}

\begin{abstract}
- Notas
1. Doutora em psicologia, psicanalista., atendimento clínico "sofrimento e trabalho", policlínica, Departamento de clínica e saúde pública do professor HERVE. CASH de Nanterre.
\end{abstract}

2. Eu agradeço a Danièle Kergoat e Pascale Molinier o tempo que elas dedicaram a esta paciente.

3. O conceito de forclusão utilizado aqui se reporta ao corpus teórico psicossomático de Christophe Dejours. Sabemos que para J. Lacan, é um mecanismo psíquico consistente na rejeição primordial de um significado fundamental fora do universo simbólico do sujeito, ligado à psicose.
4. Definição jurídica da forclusão: situação de alguém que se encontra privado do exercício de um direito por não o ter exercido em um prazo fixado.

\section{- Bibliografia}

DAVEZIES P. Eléments de psychodynamique du travai. Education Permanente, 116, 1993.

DEJOURS C. Le masculin entre sexualité et société. Adolescence, Masculin, 6, n. 6, 1988.

DEJOURS C. Travail usure mentale. Paris: Bayard, 1993.
DEJOURS C. Doctrine et théorie en psychosomatique. Revue Française de Psychosomatique, 7, 1995.

DEJOURS, C.; Dessors, D.; Molinier, P. Comprendre la résistance au changement. Documents du médecin du travail, INRS, 58, 1994.

DEJOURS C. Souffrance en France. Paris: Seuil, 1999.
DRIDA, M.; ENGEL, E.; Litzenberger, $M$. Du harcèlement ou la violence discrète des relations de travail. Actes du $2^{\text {eme }}$ CIPPT, Paris, 1999.

HIRIGOYEN, M-F. Le harcèlement moral. Paris: Syros, 1998.

MOLINIER, P. Psychodynamique du travail et précarisation: La construction défensive de la virilité. Précarisation sociale, travail et santé. CNRS/IRESCO, 1997.

PARAT, C. A propos de la répression. Revue Française de Psychosomatique. n. 1, 1991.

PEZÉ, M. Corps érotique et corps au travail: les hommes de métier. Travailler, n. 1, 1998. 